\title{
Ksilitol emdirilmiş tek kullanımlık diş fırçasının plak kaldırma etkinliğinin 10-11 yaş grubu çocuklarda in vivo olarak değerlendirilmesi
}

\author{
Tezer Ulusu, Gizem İnan, ${ }^{\star}$ Ali Affan Kurt \\ Pedodonti Anabilim Dalı, Diş Hekimliği Fakültesi, Gazi \\ Üniversitesi, Ankara, Türkiye
}

\section{ÖzeT}

AmAÇ: Bir şeker alkolü olan ksilitol mutans streptokokları tarafından fermente edilemediği için bakteri büyümesini inhibe edebilmekte ve daha az bakteriyel polisakkarit oluşturduğu için plak miktarını azaltabilmektedir. Bu çalışmada aynı firma tarafından üretilmiş, aynı özelliklere sahip ksilitol emdirilmiş ve emdirilmemiş iki ayrı diş fırçası kullanımının çocuklarda plak kaldırma etkinliğinin karşılaştırmalı olarak değerlendirilmesi amaçlandı.

GeReç Ve Yöntem: Araştırma 10-11 yaş grubu 30 çocuk hastanın 60 dişinde randomize, çift-kör şekilde yürütüldü. Çocuklar her grupta 15 çocuk yer alacak şekilde rastgele iki gruba ayrıldı ve fırçalama öncesinde plak boyama işlemi yapılarak standart koşullarda elde edilen ağıziçi fotoğraflar alındı. Bir grup, ksilitol içeren, diğer grup içermeyen tek kullanımlık diş fırçaları ile dişlerini fırçaladı. Fırçalama işlemini takiben yeniden plak boyama yapıldı ve intraoral fotoğraflar alındı. İşlemler aynı standart koșullarda gerçekleştirildi. Kayıt edilen fotoğraflarda üst santral dişlerin yüzeyindeki plak miktarı, dişlerin hangi gruba ait olduğunu bilmeyen araştırmacı tarafından Turensky Modifiye Quinley Hein Plak İndeksi kullanılarak skorlandı.

BULGULAR: Ksilitol içeren ve içermeyen her iki grupta da plak indeksi ilk değerleri, plak indeksi son değerlerine göre anlamlı derecede yüksek olarak bulgulanırken $(p<0.05)$, iki grup arasında anlamlı farklılık bulunmadı $(p>0.05)$.

Sonuç: Çalışmanın sonuçları, diş fırçasının içerisinde ksilitol olsun ya da olmasın, tek başına diş fırçalamanın plak kaldırma üzerindeki önemini gösterdi.

Anahtar Kelimeler: Diş fırçalama; diş plağı; ksilitol

KaynaK Göstermek İçin: Ulusu T, İnan G, Kurt AA. Ksilitol emdirilmiş tek kullanımlık diş fırçasının plak kaldırma etkinliğinin 10-11 yaş grubu çocuklarda in vivo olarak değerlendirilmesi. Acta Odontol Turc 2017;34(1):38-41

Makale gönderiliș tarihi: 16 Şubat. 2016; Yayına kabul tarihi: 20 Temmuz 2016 *iletișim: Gizem İnan, Gazi Üniversitesi, Diş Hekimliği Fakültesi, Pedodont Anabilim Dalı, Ankara, Türkiye;

E-posta: gizeminan_@hotmail.com
EDiтör: Levent Özer, Ankara Üniversitesi, Ankara, Türkiye

YAYIN HAKKI: () 2017 Ulusu ve ark. Bu eserin yayın hakkı Creative Commons Attribution License ile ruhsatlandırımıştır. Sınırsız kullanım, dağıtım ve her türlü ortamda çoğaltım, yazarlar ve kaynağın belirtilmesi kaydıyla serbesttir.

[Abstract in English is at the end of the manuscript]

\section{Giriş}

İnsanlarda en sık görülen enfektif oral hastalıklar olan diş çürüğü ve periodontal hastalıklar, diş yüzeyinde organize olan dental plağın etkisi ile ortaya çıkmaktadır. Bu hastalıklardan korunmak ve bu hastalıkları tedavi etmek amacıyla kullanılabilecek en önemli strateji, bakteriyel biofilmin diş yüzeyinden uzaklaştırılmasıdır. Dental plağın kaldırılmasında diş fırçası ve diş ipi gibi mekanik ajanların kullanımının basit, maliyeti düşük yöntemler olarak oldukça yeterli olduğu ancak bu yöntemlerin etkinliğinin kişinin el becerisine ve motivasyonuna bağlı olduğu bilinmektedir. Yalnızca mekanik yöntemlerle yeterli düzeyde plak kaldırmanın güçlüğü nedeniyle günümüzde araştırmacılar antimikrobiyal ajanların kullanımını önermektedirler. $\mathrm{Bu}$ nedenle son yıllarda klorheksidin glukonat, ksilitol gibi antimikrobiyal ajanların kullanımı ile mekanik plak kaldırma yöntemlerinin desteklendiği görülmektedir. ${ }^{1-4}$

Ksilitol, çeşitli meyve ve sebzelerde düşük konsantrasyonda bulunan; doğal, 5 karbonlu bir şeker alkolüdür. Çok sayıda şekersiz üründe özellikle sakız ve pastillerde yaygın olarak bulunmaktadır. Tükürük akışında artış ile birlikte mineralizasyonun uyarılması, ksilitol ve diğer tüm tatlandırıcıların dişler üzerindeki önemli ortak etkilerindendir. Ksilitolü diğer şeker alkollerinden farklı kılan en önemli özelliği ise oral bakteriler tarafından fermente edilememesidir. ${ }^{5}$ Ksilitol, mutans streptokoklarının büyümelerini, metabolizmalarını ve polisakkarit üretimlerini inhibe ederek çürükten korunma ve çürüğü kontrol altına alma amacıyla kullanılabilecek oldukça değerli bir ajandır. Düzenli ksilitol tüketiminin oral floradaki mutans streptokoklarının sayısını ve dental plak miktarını azalttığı; ayrıca anne-çocuk arasındaki potansiyel bakteri transferini de engellediği bildirilmektedir. ${ }^{6-8}$ 
Mutans streptokokların ksilitolü, major şeker taşıma yolu olan fosfoenolpiruvat fosfotransferaz sistemini kullanarak ksilitol-5-fosfat şeklinde aldıkları düşünülmektedir. Ksilitol-5-fosfat ise bu bakterilerin glikolitik enzimlerini inhibe ederek büyümelerini ve asit üretimlerini engellemektedir. ${ }^{9,10}$

Antikaryojenik etkisinden faydalanmak üzere ksilitol intiva eden sakızlar, diş macunları, gargaralar ve bebekler için geliştirilen diş temizleme mendilleri çürük profilaksisinde rutin olarak kullanılmaktadır. Son yıllarda ise fabrikasyon olarak üretilmiş tek kullanımlık ksilitol emdirilmiş diş fırçalarının da benzer amaçla kullanıımak üzere piyasaya sürüldüğü görülmektedir. ${ }^{11,12}$

$\mathrm{Bu}$ çalışmada aynı firma tarafından üretilen kıl sertliği, kıl sayısı, tüm boyutları ve fiziksel özellikleri aynı olan tek kullanımlık ksilitol emdirilmiş ve emdirilmemiş iki ayrı diş fırçasının plak kaldırma üzerindeki etkinliğinin karşılaştırmalı olarak değerlendirilmesi amaçlanmıştır.

\section{Gereç Ve Yöntem}

Çalışma için gerekli etik kurul onayı Gazi Üniversitesi Tıp Fakültesi Klinik Araştırmalar Etik Kurulu Başkanlığı'ndan alındı (23.12.2014; 25901600-3687).

Çalışma, \%95 güvenilirlik ve $\% 80$ istatistiksel kuvvet ile; 10-11 yaş grubu 30 hastanın üst sağ-sol ön kesici dişinde olmak üzere toplam 60 diş üzerinde gerçekleştirilmek üzere çift kör çalışma olarak planlandı.

Hastaların çalışmaya dahil edilme kriterleri; ağzında skorlanabilecek çürüksüz ve tamamen sürmüş üst ön kesici dişlerin mevcut olması, ağızda ortodontik aparey/ braket bulunmaması, fiziksel limitasyon bulunmaması, geçirilmiş travma hikayesi bulunmaması, ihmal edilmiş oral hijyen olmaması, yumuşak-sert doku patolojisi varlığı bulunmaması olarak belirlendi.

Gazi Üniversitesi Diş Hekimliği Fakültesi Pedodonti Anabilim Dalına rutin dental tedavileri için başvuran, bu kriterlere uyan, kendisi ve velisinin onayıyla çalışmaya dahil edilen çocuklara yapılacak ilk plak değerlendirmesi için randevu verilmiş ve öncesindeki 24 saat oral hijyen uygulamalarından kaçınması, randevudan 4 saat önce yeme-içmeyi kesmesi tembihlendi. Randevusuna gelen hastalardan ve velilerinden çalışmaya başlamadan hemen önce ayrı ayrı onam formu okutularak imzaları alındı.

Her grupta 15 çocuk yer alacak şekilde randomize olarak iki gruba ayrılan çocuklara birinci araştırmacı tarafından ilk fırçalama öncesinde oral hijyen eğitimi verilerek Modifiye Bass yöntemiyle dişlerin nasıl fırçalanacağı model üzerinde gösterilerek anlatıldı. Yine aynı araştırıcı tarafından plak boyama tableti (Mira-2-Ton, Hager Werken, Duisburg, Almanya) kullanılarak boyama yaptırıldı. Takiben tetiyer hastanın başı yaslandığında maksiller dental arkın yere paralelliği sağlanacak şekilde konumlandırılıp, fotoğraf çekme uzaklığı üst santral dişlere $15 \mathrm{~cm}$ olacak şekilde
Tablo 1. Plak indeks değerleri bakımından gruplar arasındaki farkılığa ilişkin Mann Whitney $U$ testi ve gruplarda plak indeks değerleri arasındaki farklıı̆a ilişkin Wilcoxon testi sonuçları

\begin{tabular}{|c|c|c|c|c|c|c|c|}
\hline \multicolumn{8}{|c|}{ Grup-içi } \\
\hline & & $\mathbf{n}$ & Ortalama & Ortanca & SS & $\mathbf{z}$ & $p$ \\
\hline \multirow{2}{*}{$\begin{array}{l}\text { Ksilitollü } \\
\text { fırça } \\
\text { grubu }\end{array}$} & $\begin{array}{l}\text { plak } \\
\text { indeksi } \\
\text { ilk }\end{array}$ & 30 & 3.0 & 3 & 1.4 & \multirow[b]{2}{*}{-4.615} & \multirow[b]{2}{*}{0.001} \\
\hline & $\begin{array}{l}\text { plak } \\
\text { indeksi } \\
\text { son }\end{array}$ & 30 & 1.3 & 1 & 0.9 & & \\
\hline \multirow{2}{*}{$\begin{array}{l}\text { Ksilitolsüz } \\
\text { fırça } \\
\text { grubu }\end{array}$} & $\begin{array}{l}\text { plak } \\
\text { indeksi } \\
\text { ilk }\end{array}$ & 30 & 3.4 & 3 & 1.2 & \multirow{2}{*}{-4.52} & \multirow{2}{*}{0.001} \\
\hline & $\begin{array}{l}\text { plak } \\
\text { indeksi } \\
\text { son }\end{array}$ & 30 & 1.5 & 2 & 0.8 & & \\
\hline \multicolumn{8}{|c|}{ Gruplar-arası } \\
\hline \multicolumn{5}{|c|}{$\begin{array}{l}\text { Ksilitollü vs Ksilitolsüz fırça grubu } \\
\text { (plak indeksi ilk) }\end{array}$} & \multicolumn{3}{|c|}{$z=-0.941 ; p=0.346$} \\
\hline \multicolumn{5}{|c|}{$\begin{array}{l}\text { Ksilitollü vs Ksilitolsüz fırça grubu } \\
\text { (plak indeksi son) }\end{array}$} & \multicolumn{3}{|c|}{$z=-1.063 ; p=0.288$} \\
\hline
\end{tabular}

SS: Standart sapma

ayarlanarak tüm intraoral fotoğraflar aynı araştırmacı tarafından alındı. Böylece tüm fotoğraflar standart olarak elde edildi ve bilgisayarda arşivlendi. ${ }^{13,14}$

Boyama sonrası bir gruptaki çocuklar ksilitol içeren (Happy Morning Xylitol, Hager Werken), diğer gruptaki çocuklar ksilitol içermeyen tek kullanımlık diş fırçalarıyla (Happy Morning, Hager Werken) hekim gözetimi altında, gösterilene uygun şekilde dişlerini fırçaladı. Fırçalama sırasında herhangi bir diş macunu kullanılmadı. Fırçalamayı takiben yeniden plak boyama tabletiyle plak boyama yapılarak aynı standart şartlarda fotoğraflar alındı.

Belirlenen hasta sayısına ulaşılmasından sonra bilgisayarda arşivlenen fotoğraflarda (Resim 1) üst santral dişlerin yüzeyindeki plak miktarı, işlemler sırasında hastaları hiç görmemiş, dişlerin hangi gruba ait olduğunu bilmeyen diğer araştırıcı tarafından Turensky Modifiye Quinley Hein Plak İndeksi kullanılarak skorlandı. Bu indekse göre diş yüzeyinde plak/debris bulunmayışı 0 , servikal marjinde birbirinden ayrı noktasal plak varlığı 1, servikal marjinde devamlı ince bir bant şeklinde uzanan plak varlığı 2, bir mm'den kalın kronun gingival üçlüsünü aşmayan bant şeklinde plak varlığı 3, kronun gingival üçlüsünü kaplayan ancak orta üçlüsünü aşmayan plak varlığı 4, kronun gingivalorta üçlüsünü kaplayan koronal üçlüye uzanabilen plak varlığı 5 puan olacak şekilde skorlama yapıldı.

Bu çalışmada elde edilen veriler SPSS 20 paket programı (SPSS Inc, Chicago, IL, ABD) ile analiz edildi. Her iki gruba ait fırçalama öncesi ve sonrası skorların yer aldığı sonuçların istatistiksel analizi ise Mann Whitney $\mathrm{U}$ testi ve Wilcoxon testi kullanılarak tamamlandı. 


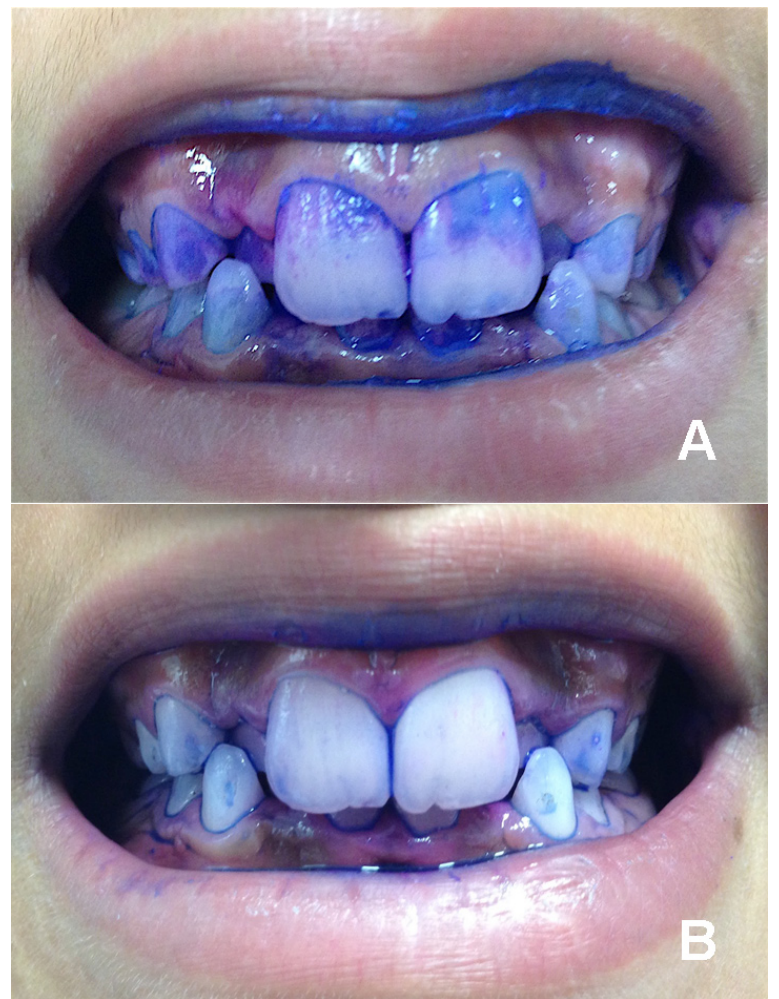

Resim 1. Plak boyama fotoğrafları; A: fırçalama öncesi, B: fırçalama sonrası

\section{BULGULAR}

Ksilitol grubunda plak indeksi ilk değerleri, plak indeksi son değerlerine göre anlamlı derecede yüksekti $(p<0.05)$. Ksilitolsüz grupta plak indeksi ilk değerleri, plak indeksi son değerlerine göre anlamlı derecede yüksekti $(p<0.05)$.

Plak indeksi ilk değerleri ve plak indeksi son değerleri bakımından ksilitollü ve ksilitolsüz diş fırçası kullanan gruplar arasında istatistiksel olarak anlamlı bir farklılık bulunmadı ( $p>0.05$; Tablo 1).

\section{TARTIŞMA}

Streptococcus mutans tarafından fermente edilemediği için asit oluşumuna neden olmaması ve S. mutans büyümesini inhibe edebilmekteki rolü bilinen ksilitol özellikle günümüz diş hekimliğinde çürük profilaksisinde kullanılmaktadır. ${ }^{15}$ Bununla beraber yine ksilitolün daha az bakteriyel polisakkarit oluşturduğu için plak miktarını azaltabildiği de bilinmektedir. ${ }^{16}$

Doğal bir şeker alkolü olan ksilitolün, sistemik olarak aşırı dozda alındığı takdirde, ozmotik diyare ve laksatif etki gibi yan etkileri olabilmektedir. Bu yan etkinin ise çocuklarda günde $15 \mathrm{gr}$ ve üstü sistemik ksilitol alımı ile görülebileceği bildirilmektedir. Bebeklik döneminde 6. aydan itibaren ksilitolün güvenle kullanılabileceği belirtilmiştir. ${ }^{17} \mathrm{Bu}$ çalışmada kullanılan fırçaların her biri sadece $0.10 \mathrm{gr}$ ksilitol içermekte ve içerdiği macunun tamamının yutulduğu varsayılsa bile günlük doz aşılmamaktadır.
Günümüzde diş yüzeyindeki plak miktarının tespitinde pek çok farklı yöntem kullanılmaktadır. Özellikle periodontal hastalıkların varlığında tedavi öncesi ve sonrası değerlendirmelerin yapılmasında, deneysel çalışmalarda, oral hijyen ürünlerinin etkinliğinin değerlendirilmesinde plağın dağılımı, derinliği ve diş yüzeyinde bulunduğu alanlar hakkında bilgi sahibi olabilmek adına bu yöntemlerin kullanılması hekimler için oldukça önemlidir. Plak miktarının ve yayılımının tespitindegelenekselyöntem, plakboyamasonrasıçeşitli indekslerin kullanımı ile plağın skorlanmasıdır. Ancak, son yıllarda intraoral fotoğraflar, QLF (Quantitative Lightinduced Fluorescence), floresan boya kullanımı sonrası dijital imaj analizi, 3-boyutlu yüzey haritalama gibi yöntemler de plak çalışmalarında kullanılmaktadır. ${ }^{18,19}$ Bu çalışmada plak boyama sonrası intraoral fotoğraflar alınarak skorlama bilgisayar üzerinde dijital görüntüler üzerinden gerçekleştirilmiştir.

Çalışmanın skorlaması intraoral fotoğraflar üzerinden yapılacağından ağız içerisinde alınan fotoğraflarda en rahat görüntülenebilen dişler olan ön keser dişler tercih edilmiştir.

Çalışmada diğer tüm özellikleri bakımından aynı olan, ksilitol içeren ve içermeyen iki diş fırçasının fırçalamayı takiben plak kaldırma üzerindeki etkisi değerlendirilmiştir.

Çalışmayı standardize edebilmek açısından en önemli hedeflerden biri, çalışmada yer alan tüm çocukların mümkün olduğu kadar aynı yöntemle ve aynı etkinlikte diş fırçalamalarını sağlamak olarak belirlenmiştir. Buna yönelik olarak; fırçalama öncesi tüm çocuklara aynı araştırmacı tarafından oral hijyen eğitimi verilerek doğru ve etkili diş fırçalama anlatılmış, plak boyaması sonrası diş fırçalama işlemi araştırmacının gözetimi altında gerçekleştirilmiştir. Böylece çocukların ve dişlerdeki plak miktarları arası karşılaştırmanın fırçalama farklılığından kaynaklı değişkenlik göstermesinin önüne geçilmesi amaçlanmıştır. Ayrıca çalışmada verilen oral hijyen eğitimi sonucunda çocukların gösterildiği üzere etkin fırçalama yapabilmesi adına motor kas faaliyetlerinin tamamen geliştiği bir dönem olan 10-11 yaş grubu tercih edildi.

Plak miktarını azaltmadaki etkisi iyi bilinen ksilitolün tek kullanımda plak miktarında önemli bir değişikliğe neden olmaması, ksilitolün bu etkisini uzun vadede plak birikimini azaltmasıyla gösterdiğini düşündürmektedir. Çalışmanın sonuçlarına göre her iki grupta da ilk ve son değerler arasında anlamlı farklılık bulunması mekanik temizliğin önemini bir kere daha göstermiştir. Bunun için yine benzer fırçalarla yapılabilecek daha uzun süreli çalışmalar bu konuda yol gösterici olabilecektir. Ancak bu şekilde planlanabilecek çalışmalarda da standardizasyon açısından çocuğun her seferinde aynı şekilde diş fırçaladığından emin olunması gerekmektedir. Aksi takdirde mekanik temizliğin farklılığından kaynaklanabilecek değişiklikler ksilitolün etkinliğinin doğru şekilde karşılaştırılabilmesinin önüne geçecektir. 
Sonuç

Çalışmanın sonuçlarına göre diş fırçalama öncesi ve sonrasında her iki grupta da farklılık görülmekle beraber, istatistiksel açıdan gruplar arası anlamlı bir fark oluşmadığı belirlenmiştir. Bu sonuç, plak kaldırma açısından en önemli faktörün mekanik temizlik olduğunu bir kere daha göstermiştir.

\section{TeŞEKKüR Ve ANMA}

Bu çalışma 2-5 Kasım 2015 tarihinde Girne'de (KKTC) düzenlenen 22. Türk Pedodonti Derneği Kongresi'nde poster olarak sunulmuştur.

Çıkar çatışması: Yazarlar bu çalışmayla ilgili herhangi bir çıkar çatışmalarının bulunmadığını bildirmişlerdir.

\section{KAYNAKLAR}

1. Papaioannou W, Vassilopoulos S, Vrostos I, Margaritis V, Panis V. A comparison of a new alcohol-free $0,2 \%$ chlorhexidine oral rinse to an established $0,2 \%$ chlorhexidine rinse with alcohol for the control of dental plaque accumulation. Int J Dent Hyg 2016;14:272-7.

2. Supranoto SC, Slot DE, Addy M, Van der Weijden GA. The effect of chlorhexidine dentifrice or gel versus chlorhexidine mouthwash on plaque, gingivitis, bleeding and tooth discoloration: a systematic review. Int J Dent Hyg 2015;13:83-92.

3. Slot DE, Berchier CE, Addy M, Van der Velden U, Van der Weijden GA. The efficacy of chlorhexidine dentifrice or gel on plaque, clinical parameters of gingival inflammation and tooth discoloration: a systematic review. Int J Dent Hyg 2014;12:25-35.

4. Nayak PA, Nayak UA, Mythili R. Effect of Manuka honey, chlorhexidine gluconate and xylitol on the clinical levels of dental plaque. Contemp Clin Dent 2010;4:214-7.

5. Bahador A, Lesan S, Kashi N. Effect of xylitol on cariogenic and beneficial oral sterptococci: a randomized, double blind crossover trial. Iran J Microbiol 2012;2:75-81.

6. Subramaniam P, Nandan N. Effect of xylitol, sodium fluoride and triclosan containing mouth rinse on Streptococcus mutans. Contemp Clin Dent 2011;4:287-90.

7. Söderling $E$, Isokangas $P$, Pienihäkkinen $K$, Tenovuo J, Alanen $P$. Influence of maternal xylitol consumption on mother-child transmission of mutans streptococci: 6-year follow-up. Caries Res 2001;35:173-7.

8. Isokangas $P$, Söderling E, Pienihäkkinen K, Alanen P. Occurrence of dental decay in children after maternal consumption of xylitol chewing gum, a follow-up from 0 to 5 years of age. J Dent Res 2000;79:1885-9.

9. Söderling EM. Xylitol, Mutans Streptococci and Dental Plaque. Adv Dent Res 2009;21:74-8.

10. Söderling E, Hirvonen A, Karjalainen S, Fontana M, Catt D, Seppa L. The effect of xylitol on the composition of the oral flora: a pilot study. Eur J Dent 2011;5:24-31.

11. Kumar S, Sogi SH, Indushekar KR. Comparative evaluation of the effects of xylitol and sugar-free chewing gums on salivary and dental plaque pH in children. J Indian Soc Pedod Prev Dent 2013;31:240-4.

12. Zhan L, Cheng J, Chang $P$, Ngo M, Den Besten PK, Hoover Cl, et al. Effects of xylitol wipes on cariogenic bacteria and caries in young children. J Dent Res 2012;91:85-90

13. Pretty IA, Edgar WM, Smith PW, Higham SM. Quantification of dental plaque in the research environment. J Dent 2015;33:193-207.
14. Kelly A, Antonio AG, Maia LC, Luiz RR. Reliability assessment of a plaque scoring index using photographs. Methods Inf Med 2008;47:443-7.

15. Söderling E, EISalhy M, Honkala E, Fontana M, Flannagan S, Eckert G, et al. Effects of short-term xylitol gum chewing on the oral microbiome. Clin Oral Investig 2015;19:237-44.

16. Kumar S, Sogi SH, Indushekar KR. Comparative evaluation of the effects of xylitol and sugar-free chewing gums on salivary and dental plaque pH in children. J Indian Soc Pedod Prev Dent 2013;31:240-4.

17. Vernacchio L, Corwin MJ, Vezina RM, Pelton SI, Feldman HA, Coyne-Beasley $\mathrm{T}$, et al. Xylitol syrup for the prevention of acute otitis media. Pediatrics 2014;133:289-95.

18. Carter K, Landini G, Walmsley AD. Automated quantification of dental plaque accumulation using digital imaging. J Dent 2004;32:623-8.

19. Raggio DP, Braga MM, Rodrigues JA, Freitas PM. Reliability and discriminatory power of methods for dental plaque quantification. J Appl Oral Sci 2010;2:186-93

\section{Evaluation of the plaque removal efficacy of xylitol-impregnated single-use toothbrush in vivo in 10-11-year-old children}

\section{Abstract}

OвJeCtive: Xylitol is non-fermentable by oral bacteria and it inhibits the growth, metabolism and polysaccharide production of mutans streptococci, resulting in less bacterial plaque accumulation on teeth. This study aimed to compare the plaque removal efficacy on the teeth of children of xylitol-impregnated or non-impregnated singleuse toothbrushes identical in shape and manufactured by the same company.

Materials ANd Method: Thirty children aged 10-11 years were randomly separated into two groups of 15 children each. First group used a xylitol-impregnated toothbrush and the second group used a non-impregnated toothbrush for brushing. Dental plaque on upper central incisors was photographed intra-orally before and after brushing under standardized conditions. These photographs were stored in a computer and the amount of dental plaque was scored by using Turensky Modified Quinley Hein Plaque Index by a researcher blinded to the groups.

RESULTS: While both xylitol-impregnated and nonimpregnated groups had significantly higher plaque index in before-brushing photographs than after-brushing photographs $(p<0.05)$, no significant difference existed between the two groups $(p>0.05)$.

ConcLusion: The results of the study emphasized that toothbrushing itself, regardless of xylitol content within the toothbrush, is essential for removing the dental plaque.

KEYWORDS: Dental plaque; toothbrushing; xylitol 